\title{
Bumblebees as potential indicators for the evaluation of habitat quality
}

\author{
I. Diaz-Forero, V. Kuusemets, M. Mänd \& J. Luig \\ Institute of Agricultural and Environmental Sciences, \\ Estonian University of Life Sciences, Estonia
}

\begin{abstract}
Habitat fragmentation, decline and degradation are considered important threats to biodiversity and the principal processes that contribute to landscape change. It is fundamental to understand the quality of habitats (and the location of suitable ones) to develop appropriate biodiversity conservation strategies. Insects are considered key indicators of environmental change due to their diversity of habitat characteristics and requirements. Habitat quality may be assessed by its suitability for insects using important ecological differences between generalist and specialist species. Specialist species are more severely affected by the degradation and decrease of suitable habitats than generalists, as they are dependent on specific types of flowering plants or local environments. In our study, we collected data on five species of long-tongued bumblebees (gen. Bombus) including B. pascuorum, B. hortorum, B. ruderarius, B. sylvarum and $B$. distinguedus. The richness and abundance of long-tongued bumblebee species were recorded in 22 semi-natural meadows in Northeast Estonia. We identified abiotic and biotic factors, at both patch and landscape scale, which significantly impacted total species richness and abundance of long-tongued bumblebees. Overall, we found that besides the availability of food resources in the habitat, it is important to bear in mind the quality and diversity of the surrounding matrix when designing biodiversity conservation strategies. In countries with patchy landscapes, like Estonia, it is important to consider ecological indicators that are strongly associated with both patch and landscape variables. Therefore, bumblebees have the potential to serve as good indicator species for habitat quality.
\end{abstract}

Keywords: long-tongued bumblebees, species richness, flowering plants, landscape structure. 


\section{Introduction}

The main processes that contribute to landscape change are habitat fragmentation, decline and degradation; these are also important threats to biodiversity [1]. Fischer and Lindenmayer [1] considered habitat degradation to be the gradual deterioration in quality of an area of habitat for a given species. Many definitions have been given to habitat quality [2]. In our study, we adopted the one presented by Hall et al. [3]; they defined habitat quality as "the ability of the environment to provide conditions appropriate for individual and population persistence".

It is well known and widely accepted in many countries that bumblebees and other important pollinators are declining [4-7]. The intensification of agriculture has led to the reduction of suitable habitats and decrease of food resources for pollinators $[8,9]$. It is fundamental to become acquainted with the quality of the remaining habitats and the location of suitable ones in order to develop appropriate biodiversity conservation strategies. To do that, we must know what indicators can be used to evaluate habitat quality.

Long-tongued bumblebees are important pollinators of deep perennial flowers. Longer-tongued species have shown increasing vulnerability in the United Kingdom. Goulson et al. [10] found that "the most severely affected species tend to be those with long tongues associated with deep perennial flowers". In contrast, Williams and Osborne [7] found that long tongues and food-plant specialisation were not associated with declines of bumblebee species. However, some studies agreed that further research is required on the ecology of rare species and the role of diet specialisation in bumblebee decline (e.g. $[4,7,11])$.

In our study, we collected field data on five species of long-tongued bumblebees: B. pascuorum, B. hortorum, B. ruderarius, B. sylvarum and B. distinguendus. We identified biotic and abiotic factors, at both patch and landscape scale, which may be significant indicators for species richness and abundance of long-tongued bumblebees. In addition, we discuss why bumblebees could be used as potential indicators of habitat quality.

\section{Materials and methods}

We completed field work during the summers of 2008 and 2009 in Ida-Virumaa, a county in northeast Estonia. This region has a very patchy landscape mosaic with a variety of land cover types, predominantly forest, arable land and meadow. Even though northeastern Estonia has been impacted by mining activities, it is still considered a region that supports a significant number of species and abundance of pollinators, including bumblebees [12]. In both years, we visited 22 semi-natural meadows and sampled each meadow two times. Bumblebee counts took place in June, July and August, and were completed within approximately 45 minutes. We performed systematic walking surveys [13] during the warmer part of the day, between 11:00 $\mathrm{h}$ and 16:00 $\mathrm{h}$, when weather conditions were suitable (i.e., temperature was above $18^{\circ} \mathrm{C}$ and wind 
speed was less than 5 as measured by the Beaufort scale). The identification of species and counting of individual bumblebees was done by sight. When the observer could not identify the species, the bumblebee was caught with an insect net for later identification. The nomenclature of the insects follows that used in the Fauna Europaea Web Service [14]. In this study, we used our data on total species richness and abundance of long-tongued (LT) bumblebees (i.e., $B$. pascuorum, B. hortorum, B. ruderarius, B sylvarum and B. distinguendus).

At patch scale, we measured the following variables: species richness of flowering plants, percent cover of flowering plants, patch area, shape, fractal dimension index and edge density. We identified the flowering plants and counted the number of species on site. Percent cover of flowering plants was recorded via a visual estimation of the overall coverage at each study site. We used the total number of species of flowering plants and the arithmetic means of the four observations of percent cover of flowering plants. At landscape scale, we considered the following indices: patch richness density (PRD), interspersion and juxtaposition index (IJI), edge density at landscape level (ED_Land) and Shannon's diversity index (SHDI). In addition, we calculated the proportion of different land cover types around the study areas (i.e., arable land, meadow, forest and human settlements). Calculations were performed with ArcGIS 9.3 software using the digital Estonian Basic Map provided by the Estonian Land Board at a scale of 1:10,000. All landscape variables were estimated at four spatial scales $(250,500,1000$ and $2000 \mathrm{~m}$ radius). Fragstats software (Version 3.3) was used to compute the patch and landscape indices.

In this study, Spearman rank order correlations were performed to analyse the relationships between species richness or abundance of long-tongued bumblebees and our variables at patch and landscape scale.

\section{Results and discussion}

\subsection{Long-tongued (LT) bumblebees and their relationships with patch and landscape variables}

We found five species of LT bumblebees: $B$. pascuorum, B. hortorum, $B$. ruderarius, $B$. sylvarum and $B$. distinguendus. Total species richness and abundance of LT bumblebees ranged from 1 to 4 species and from 2 to 29 individuals, respectively. The most abundant species were $B$. pascuorum and $B$. ruderarius, whereas $B$. distinguendus was extremely rare.

The results from correlation analyses are presented in Table 1 . We found that both species richness and abundance of LT bumblebees had positive relationships with species richness of flowering plants and percent cover of flowering plants. The higher the availability and diversity of food resources in the habitat, the better the bumblebees' chances of finding the flowering plant species they require. In addition, the dispersal distances of some rare species of bumblebees are very restricted, depending on resources within the habitat or in compensating areas, such as edges. Some rare, long-tongued species have a rather small foraging range (e.g., B. distinguendus) [15]. In general, increasing 
the presence of flowering plant species in semi-natural meadows enhances both the species richness and abundance of bumblebees by providing better quality habitats. This is consistent with previous studies on bumblebees (e.g. $[5,11,16])$.

Table 1: Relationships between long-tongued bumblebees and variables at patch and landscape scale.

\begin{tabular}{|c|c|c|c|}
\hline Variable & $\begin{array}{c}\text { Spatial scale } \\
\text { (m radius) }\end{array}$ & \multicolumn{2}{|c|}{ Long-tongued bumblebees } \\
\cline { 2 - 4 } & - & Species richness $^{\mathrm{a}}$ & Abundance $^{\mathrm{a}}$ \\
\hline $\begin{array}{c}\text { Flowering } \\
\text { plant species } \\
\text { richness }\end{array}$ & & $0.67^{* * *}$ & $0.76^{* * *}$ \\
\hline $\begin{array}{c}\text { Percent cover } \\
\text { of flowering } \\
\text { plants }\end{array}$ & - & $0.61^{* *}$ & $0.58^{* *}$ \\
\hline $\begin{array}{c}\text { Proportion of } \\
\text { forest (\%) }\end{array}$ & 500 & & $-0.45^{*}$ \\
\hline $\begin{array}{c}\text { Proportion of } \\
\text { meadows (\%) }\end{array}$ & 1000 & $-0.45^{*}$ & -0.01 \\
\cline { 2 - 4 } $\begin{array}{c}\text { Edge density } \\
\text { at landscape } \\
\text { level }\end{array}$ & 2000 & $0.55^{* *}$ & 0.09 \\
\cline { 2 - 4 } $\begin{array}{c}\text { (ED_Land) } \\
\text { (m/ha) }\end{array}$ & 1000 & $0.58^{* *}$ & 0.10 \\
\hline $\begin{array}{c}\text { Shannon's } \\
\text { diversity } \\
\text { index (SHDI) }\end{array}$ & 2000 & 0.27 & $0.42^{*}$ \\
\hline
\end{tabular}

${ }^{\mathrm{a}}$ Spearman rank correlation coefficients $\left(r_{s}\right)$ are shown

* Correlations significant at $P<0.05$

** Correlations significant at $P<0.01$

*** Correlations significant at $P<0.001$

At landscape scale, we found that species richness of LT bumblebees correlated positively with proportion of meadows at $1000 \mathrm{~m}$ and $2000 \mathrm{~m}$. Similarly, Hatfield and LeBuhn [17] found that the most consistent positive influence on species richness and abundance of bumblebees was the proportion of meadows in the surrounding landscape, at a 2-km buffer from the edge of the focal habitat. In general, bumblebees have large foraging ranges [17-19]. Even though some LT bumblebee species have short foraging distances, as mentioned above, other species are known to fly more than $2000 \mathrm{~m}$ (e.g., B. pascuorum) [20]. Dispersal abilities of bumblebees allow them to retrieve floral resources in adjacent meadows, increasing the probability of individuals finding flowering plants [17].

In addition, LT bumblebee abundance correlated positively with ED_Land at $500 \mathrm{~m}$ and $1000 \mathrm{~m}$. There is a strong dependency of bumblebee abundance on the availability of flowering plants. Kumar et al. [13] explained that habitat 
edges contain a great abundance and diversity of floral resources, making them suitable places for flower visitors. Also, the presence of edges and other compensating areas is very important to bumblebee survival, especially in patchy landscapes with diverse land cover types. Sepp et al. [21] explained that forest edges are particularly important in April and May, when bumblebee queens mostly forage flowering willows that are commonly found in the forest edges of Estonia.

Positive relationships were found between species richness of LT bumblebees and SHDI at $2000 \mathrm{~m}$. This landscape index indicates the level of complexity of the surrounding matrix, as the higher the value of SHDI, the higher the number of patch types and the more equitable the distribution of those patch types across the landscape [22]. Other authors have found similar positive relationships between insects and the diversity of the landscape matrix [23, 24]. Williams and Osborne [7] suggested that the ability of bumblebees to fly long distances from the colony makes them less susceptible to the fragmentation and patchiness of the landscape, as they become more flexible in the utilisation of food resources. The presence of different patch types in the surrounding landscape of their habitats increases the probabilities of finding suitable habitat fragments with the needed flowering plant species; concurrently, this enhances the survival possibility of bumblebee species.

In contrast, negative correlations were found between species richness of LT bumblebees and proportion of forest at $500 \mathrm{~m}$ and $1000 \mathrm{~m}$. These results suggest that some species of LT bumblebees prefer open areas. In general, LT bumblebee species have specialised diets and are expected to visit a particular type of flowering plants; those flowers are more likely to be found in open areas than in patches of forest. Similarly, Bäckman and Tiainen [16] found that the longtongued species B. ruderarius prefers open habitats. Additionally, it has been suggested that early-emerging bumblebee species are associated with forests while late-emerging species are associated with grasslands; most late-emerging species are medium or long-tongued bumblebees [11].

Other variables at patch scale (i.e., patch area, shape, fractal dimension index and edge density) and landscape scale (i.e., proportion of arable land, proportion of human settlements, PRD and IJI) do not appear to be important for LT bumblebee species richness and abundance.

\subsection{Bumblebees as potential indicators of habitat quality}

Ecological indicators can be defined as factors that communicate important information about ecosystems and the impact of human activities on them. Ecosystems are complex and the use of ecological indicators is needed in order to describe them in simpler terms that can be understood and used by scientists and non-scientists alike to make management decisions [25].

Insects are considered key indicators of environmental change due to their diversity of habitat characteristics and requirements. The role of insects as ecological indicators has been tested and studied extensively (e.g. [21, 26]). Bees are a vital element of global biodiversity and an important group of pollinators, as they play a key role in supporting not only crops, but also the diversity of 
natural and semi-natural vegetation $[27,28]$ and the survival of other organisms $[4,27]$. Among bees, bumblebees are considered to be the best-documented group [6]. Bumblebees are known to be sensitive to environmental changes and serve as good indicators of habitat quality [21,29].

In Estonia, bumblebees are considered significant indicators of habitat and landscape diversity [5], and have been proposed as biodiversity indicators at the landscape level of the agri-environmental programme [21]. As we mentioned above, bumblebees and other pollinators are at risk. Thus, there is a current need for the protection of endangered species as well as the conservation of their habitats. Semi-natural habitats, such as meadows, are areas of important value for bumblebees, as they provide essential resources like food and nesting sites $[30,31]$. In a recent study, Le Féon et al. [32] found that bees were negatively associated with agricultural intensification, while they were affected positively by the amount of semi-natural habitats in the surrounding landscape. Some conservationists' studies of endangered species have emphasised the role and importance of large-scale dynamics (e.g. [27]); it therefore appears relevant to consider interactions between species and landscape elements when developing biodiversity conservation strategies.

Hatfield and LeBuhn [17] suggested that bumblebee communities provide an excellent model for evaluating the importance of factors at patch and landscape scale. Even though bumblebees are known to have large foraging distances [1719], they appear to display a high dependency on their central foraging place [17, 33]. Our results show that bumblebees are related with variables at patch scale (i.e., species richness of flowering plants and percent cover of flowering plants) as well as variables at landscape scale (i.e., proportion of meadows, proportion of forest, ED_Land and SHDI) in different ways.

Habitat quality may be assessed by its suitability for insects [34] using important ecological differences between generalists and specialist species. Specialist species are more susceptible to degradation and decrease of suitable habitats than generalists because they are dependent on specific types of habitats or flowering plants. A greater tongue length in bumblebees has been suggested as one factor that confers greater susceptibility to decline on some bumblebee species [7].

\section{Conclusions}

Overall, we found that not only the availability of food resources at patch level, but also the quality and diversity of the surrounding matrix, are important factors affecting the species richness and abundance of long-tongued bumblebees. Landscapes with high percentages of meadows, with a strong presence of edges and a diverse matrix, may support a higher diversity and abundance of longtongued bumblebees. With the presence of adjacent patches of meadow and habitat edges in the surrounding landscape, there is an increased probability that bumblebees will encounter floral resources during their life cycle. In addition, it appears that the ability of bumblebees to fly long distances makes them less vulnerable to the level of fragmentation and patchiness in a given landscape. 
In countries with patchy landscapes, like Estonia, it is important to consider ecological indicators that are strongly associated with both patch and landscape variables. Bumblebees, because of their reliance on these variables, have the potential to serve as accurate indicators of habitat quality.

\section{References}

[1] Fischer, J. \& Lindenmayer, D.B., Landscape modification and habitat fragmentation: a synthesis. Global Ecology and Biogeography, 16(3), pp. 265-280, 2007.

[2] Mortelliti, A., Amori, G. \& Boitani, L., The role of habitat quality in fragmented landscapes: a conceptual overview and prospectus for future research. Oecologia, 163(2), pp. 535-547, 2010.

[3] Hall, L.S., Krausman, P.R. \& Morrison, M.L., The habitat concept and a plea for standard terminology. Wildlife Society Bulletin, 25, pp. 173-182, 1997.

[4] Goulson, D., Hanley, M.E., Darvill, B. \& Ellis, J.S., Biotope associations and the decline of bumblebees (Bombus spp.). Journal of Insect Conservation, 10(2), pp. 95-103, 2006.

[5] Mänd, M., Mänd, R. \& Williams, I.H., Bumblebees in the agricultural landscape of Estonia. Agriculture, Ecosystems \& Environment, 89(1-2), pp. 69-76, 2002.

[6] Potts, S.G., Biesmeijer, J.C., Kremen, C., Neumann, P., Schweiger, O. \& Kunin, W.E., Global pollinator declines: trends, impacts and drivers. Trends in Ecology and Evolution, 25(6), pp. 345-353, 2010.

[7] Williams, P.H. \& Osborne, J.L., Bumblebee vulnerability and conservation world-wide. Apidologie, 40(3), pp. 367-387, 2009.

[8] Carvell, C., Habitat use and conservation of bumblebees (Bombus spp.) under different grassland management regimes. Biological Conservation, 103(1), pp. 33-49, 2002.

[9] Xie, Z., Williams, P.H. \& Tang, Y., The effect of grazing on bumblebees in the high rangelands of the eastern Tibetan Plateau of Sichuan. Journal of Insect Conservation, 12(6), pp. 695-703, 2008.

[10] Goulson, D., Lye, G.C. \& Darvill, B., Decline and conservation of bumblebees. Annual Review of Entomology, 53, pp. 191-208, 2008.

[11] Goulson, D., Hanley, M.E., Darvill, B., Ellis, J.S. \& Knight, M.E., Causes of rarity in bumblebees. Biological Conservation, 122(1), pp. 1-8, 2005.

[12] Diaz-Forero, I., Liivamägi, A., Kuusemets, V. \& Luig, J., Pollinator richness and abundance in Northeast Estonia: bumblebees, butterflies and dayflying moths. Forestry Studies | Metsanduslikud Uurimused, 53, pp. 5$14,2010$.

[13] Kumar, S., Simonson, S.E. \& Stohlgren, T.J., Effects of spatial heterogeneity on butterfly species richness in Rocky Mountain National Park, CO, USA. Biodiversity and Conservation, 18(3), pp. 739-763, 2009.

[14] Fauna Europaea Web Service. www.faunaeur.org 
[15] Charman, T.G., Sears, J., Green, R.E. \& Bourke, A.F.G., Conservation genetics, foraging distance and nest density of the scarce Great Yellow Bumblebee (Bombus distinguendus). Molecular Ecology, 19(13), pp. 26612674, 2010.

[16] Bäckman, J.P. \& Tianen, J., Habitat quality of field margins in a Finnish farmland area for bumblebees (Hymenoptera: Bombus and Psithyrus). Agriculture, Ecosystems \& Environment, 89(1-2), pp. 53-68, 2002.

[17] Hatfield, R.G. \& LeBuhn, G., Patch and landscape factors shape community assemblage of bumble bees, Bombus spp. (Hymenoptera: Apidae), in montane meadows. Biological Conservation, 139(1-2), pp. 150-158, 2007.

[18] Steffan-Dewenter, I., Münzenberg, U., Bürger, C., Thies, C. \& Tscharntke, T., Scale-dependent effects of landscape context on three pollinator guilds. Ecology, 83(5), pp. 1421-1432, 2002.

[19] Westphal, C., Steffan-Dewenter, I. \& Tscharntke, T., Bumblebees experience landscapes at different spatial scales: possible implications for coexistence. Oecologia, 149(2), pp. 289-300, 2006.

[20] Zurbuchen, A., Landert, L., Klaiber, J. Muller, A., Hein, S. \& Dorn, S., Maximum foraging ranges in solitary bees: only a few individuals have the capability to cover long foraging distances. Biological Conservation, 143(3), pp. 669-676, 2010.

[21] Sepp, K., Mikk, M., Mänd, M. \& Truu, J. Bumblebee communities as an indicator for landscape monitoring in the agri-environmental programme. Landscape and Urban Planning, 67(1-4), pp. 173-183, 2004.

[22] Eiden, G., Kayadjanian, M. \& Vidal, C., From land cover to landscape diversity in the European Union, Chapter 1. Capturing landscape structures: Tools. ec.europa.eu/agriculture/publi/landscape/ch1.htm

[23] Kivinen, S., Luoto, M., Kuussaari, M. \& Helenius, J., Multi-species richness of boreal agricultural landscapes: effects of climate, biotope, soil and geographical location. Journal of Biogeography, 33(5), pp. 862-875, 2006.

[24] Steffan-Dewenter, I., Importance of habitat area and landscape context for species richness of bees and wasps in fragmented orchard meadows. Conservation biology, 17(4), pp. 1036-1044, 2003.

[25] Girardin, P., Bockstaller, C. \& Van der Werf, H., Indicators: Tools to evaluate the environmental impacts of farming systems. Journal of Sustainable Agriculture, 13(4), pp. 6-21, 1999.

[26] Billeter, R., Liira, J., Bailey, D., Bugter, R., Arens, P., Augenstein, I., Aviron, S., Baudry, J., Bukacek, R., Burel, F., Cerny, M., De Blust, G., De Cock, R., Diekotter, T., Dietz, H., Dirksen, J., Dormann, C., Durka, W., Frenzel, M., Hamersky, R., Hendrickx, F., Herzog, F., Klotz, S., Koolstra, B., Lausch, A., Le Coeur, D., Maelfait, J.P., Opdam, P., Roubalova, M., Schermann, A., Schermann, N., Schmidt, T., Schweiger, O., Smulders, M.J.M., Speelmans, M., Simova, P., Verboom, J., van Wingerden, W.K.R.E., Zobel, M. \& Edwards, P.J., Indicators for biodiversity in 
agricultural landscapes: a pan-European study. Journal of Applied Ecology, 45(1), pp. 141-150, 2008.

[27] Goulson, D., Rayner, P., Dawson, B. \& Darvill, B., Translating research into action; bumblebee conservation as a case study. Journal of Applied Ecology, 48(1), pp. 3-8, 2011.

[28] Rundlöf, M., Nilsson, H. \& Smith, H.G., Interacting effects of farming practice and landscape context on bumble bees. Biological Conservation, 141(2), pp. 417-426, 2008.

[29] Haaland, C. \& Gyllin, M., Butterflies and bumblebees in greenways and sown wildflower strips in southern Sweden. Journal of Insect Conservation, 14(2), pp. 125-132, 2010.

[30] Kells, A.R. \& Goulson, D., Preferred nesting sites of bumblebee queens (Hymenoptera: Apidae) in agroecosystems in the UK. Biological Conservation, 109(2), pp. 165-174, 2003.

[31] Svensson, B., Langerlöf, J. \& Svensson, B.G., Habitat preferences of nestseeking bumble bees (Hymenoptera: Apidae) in an agricultural landscape. Agriculture Ecosystems \& Environment, 77(3), pp. 247-255, 2000.

[32] Le Féon, V., Schermann-Legionneta, A., Delettrea, Y., Avironb, S., Billeterc, R., Bugterd, R., Hendrickxe, F. \& Burel, F., Intensification of agriculture, landscape composition and wild bee communities: A large scale study in four European countries. Agriculture, Ecosystems \& Environment, 137(1-2), pp. 143-150, 2010.

[33] Osborne, J.L. \& Williams, I.H., Site constancy of bumble bees in an experimentally patchy habitat. Agriculture Ecosystems \& Environment, 83 (1-2), pp. 129-141, 2001.

[34] Fahrig, L. \& Jonsen, J., Effect of habitat patch characteristics on abundance and diversity of insects in an agricultural landscape. Ecosystems, 1(2), pp. 197-205, 1998. 